Article

\title{
Proteomic Changes during MCMV Infection Revealed by iTRAQ Quantitative Proteomic Analysis in Maize
}

\author{
Mingqing Dang ${ }^{1}$, Qi Cheng ${ }^{1}$, Ya $\mathrm{Hu}^{1}{ }^{1}$, Jianxiang $\mathrm{Wu}^{1}{ }^{1}$, Xueping Zhou ${ }^{1,2}$ and Yajuan Qian ${ }^{1, *}$ \\ 1 State Key Laboratory of Rice Biology, Institute of Biotechnology, Zhejiang University, \\ Hangzhou 310058, China; dangmingqing2008@163.com (M.D.); 21716069@zju.edu.cn (Q.C.); \\ 21616132@zju.edu.cn (Y.H.); wujx@zju.edu.cn (J.W.); zzhou@zju.edu.cn (X.Z.) \\ 2 State Key Laboratory for Biology of Plant Diseases and Insect Pests, Institute of Plant Protection, \\ Chinese Academy of Agricultural Sciences, Beijing 100193, China \\ * Correspondence: yjqian@zju.edu.cn; Tel.: +86-571-88982677
}

Received: 11 November 2019; Accepted: 17 December 2019; Published: 19 December 2019

\begin{abstract}
Maize chlorotic mottle virus (MCMV) has been occurring frequently worldwide and causes severe yield losses in maize (Zea mays). To better investigate the destructive effects of MCMV infection on maize plants, isobaric tagging for relative and absolute quantitation (iTRAQ)-based comparative proteomic analysis was performed on MCMV infected maize cv. B73. A total of 972 differentially abundant proteins (DAPs), including 661 proteins with increased abundance and 311 proteins with reduced abundance, were identified in response to MCMV infection. Functional annotations of DAPs and measurement of photosynthetic activity revealed that photosynthesis was decreased, while the abundance of ribosomal proteins, proteins related to stress responses, oxidation-reduction and redox homeostasis was altered significantly during MCMV infection. Two DAPs, disulfide isomerases like protein ZmPDIL-1 and peroxiredoxin family protein ZmPrx5, were further analyzed for their roles during MCMV infection through cucumber mosaic virus-based virus-induced gene silencing (CMV-VIGS). The accumulation of MCMV was suppressed in ZmPDIL-1-silenced or ZmPrx5-silenced B73 maize, suggesting ZmPDIL-1 and ZmPrx5 might enhance host susceptibility to MCMV infection.
\end{abstract}

Keywords: maize chlorotic mottle virus; iTRAQ; photosynthesis; disulfide isomerases; peroxiredoxin; VIGS

\section{Introduction}

Plants are generally exposed to diverse biotic and abiotic stresses that significantly affects plant growth and development. In order to defend against pathogen attacks, plants trigger overlapping sets of defense responses including activation of secondary metabolites and hormone signaling, reducing photosynthesis, accumulation of reactive oxygen species and callose, reinforcement of the cell walls, and rearrangement of cytoskeleton [1-7]. Extensive studies of comparative transcriptional and proteomic analysis revealed the roles of transcriptional reprogramming of defense genes and posttranslational modification of proteins in plant immunity to pathogens [2,8-10].

Maize is an important staple food and energy crop worldwide. However, the quality as well as production of maize are always threatened by pathogen invasion. Several RNA viruses-such as sugarcane mosaic virus (SCMV), rice black streaked dwarf (RBSDV), maize dwarf mosaic virus (MDMV), maize rough dwarf virus (MRDV), and maize chlorotic mottle virus (MCMV) - have been reported as common viral agents infecting maize [11-13]. Synergistic interactions of MCMV with potyviruses, such as wheat streak mosaic rymovirus or SCMV, are fairly common in maize fields [13,14].

MCMV, which comprises a linear, positive sense, single-stranded RNA of 4436 nucleotides (nt), is the only member in the genus Machlomovirus, family Tombusviridae. Two subgenomic RNAs (sgRNAs), 
named as sgRNA1 and sgRNA2, are transcribed during the viral infection process [15]. The first open reading frame (ORF) in the MCMV genomic RNA (gRNA) encodes a P32 protein unique to MCMV. A former study showed MCMV accumulation and the severity of viral symptoms were dramatically decreased in the absence of P32 [16]. The P50 protein and its stop codon readthrough protein, P111 (the ratio of P50 to P111 is still unclear), are related to highly conserved RNA dependent RNA polymerases (RdRps) encoded by other members in the family Tombusviridae $[15,16]$. In the 3'-terminal third of the genome, several ORFs are expressed from sgRNA1 [17]. The first ORF in sgRNA1 encodes the P7a and a P7a stop codon readthrough product known as the P31 protein. A small ORF after the P7a ORF, known as P7b, was identified recently [16]. P7a and P7b proteins are closely related to the movement protein 1 (MP1) of viruses in the family Tombusviridae or MP2 encoded by panicoviruses [18,19], which are required for MCMV cell-to-cell movement. The P31 protein facilitates virus systemic infection in plants [16]. The second AUG codon on sgRNA1 encodes the MCMV coat protein (CP) [17]. A $337 \mathrm{nt} \mathrm{sgRNA2} \mathrm{was} \mathrm{also} \mathrm{found} \mathrm{in} \mathrm{MCMV-infected} \mathrm{protoplasts} \mathrm{and} \mathrm{plants} \mathrm{[17].}$

Through RNA-Seq, many differentially expressed genes were identified to associate with plant pathogen infection in maize [20-24]. For example, gene expression profile analysis revealed that the brassinosteroid (BR) pathway was significantly altered after MCMV-infected maize plants [22]. However, posttranslational modifications usually modulate gene expression and protein accumulation, the transcriptional levels do not correlate well with the protein abundances. Therefore, the analysis of differential protein profile might be a more efficient way to accurately discover the key factors participating in plant immunity to pathogens. Proteomic analysis of maize-virus interactions have addressed the effect of SCMV, RBSDV, or MDMV on maize protein abundance [11,25-27]. However, to our knowledge, scarcely any proteomic datasets in response to MCMV infection have been reported. To effectively determine the molecular mechanism(s) underlying MCMV infection, we used the isobaric tags for relative and absolute quantification (iTRAQ)-based comparative proteomic approach to analyze maize cv. B73 plants infected with MCMV. The results of the present study provide a detailed whole-proteome information on the effects of MCMV infection in maize.

\section{Results}

\subsection{Phenotype Shown on MCMV-Infected Maize Plants}

Four-leaf stage maize plants were inoculated with crude extracts from MCMV-infected leaf tissues and periodically monitored for disease symptom. All the inoculated seedlings developed mosaic symptoms in their young leaves at $11 \mathrm{dpi}$ (Figure 1A). To determine the accumulated levels of MCMV in systemically infected leaves, tissues were collected and tested using ELISA. The MCMV titer was markedly higher in the MCMV-infected samples than that in those mock-inoculated control plants (Figure 1B). Further confirmation was obtained using qRT-PCR and northern blot, which showed that the accumulation levels of MCMV gRNA were remarkably increased in the MCMV-infected samples compared with those controlled samples (Figure 1C,D). 
A

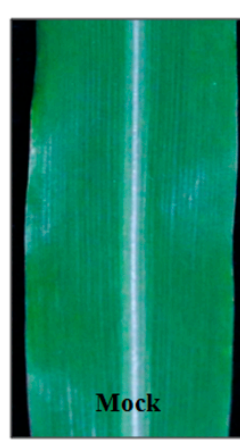

B

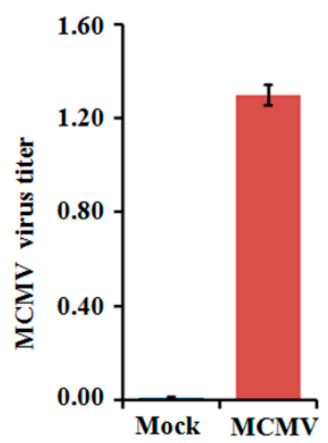

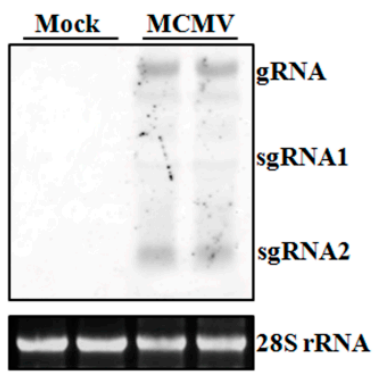

C

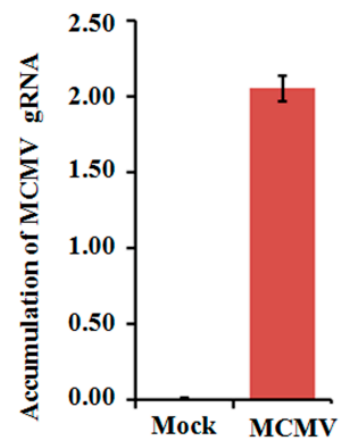

Figure 1. Assays of maize cv B73 plants inoculated with MCMV. (A) Typical symptom induced by MCMV infection. The leaves were photographed at 11 dpi. (B) Detection of MCMV accumulation by ELISA using an anti-MCMV monoclonal antibody. (C,D) Detection of MCMV gRNA accumulations by qRT-PCR using MCMV specific primers or northern blot using MCMV specific probe. Bars indicate the means \pm standard deviations (SD) from three independent experiments.

\section{2. iTRAQ-Based Proteomic Analysis}

In order to identify the differentially abundant proteins responsive to MCMV infection, total proteins were extracted from the MCMV-infected or mock-inoculated maize seedlings and detected using comparative iTRAQ analysis. About 333,899 spectra were obtained between the two groups and 73,966 of them were matched to known spectra using the Mascot analysis software. From the 60,212 unique spectra obtained, 13,606 peptides were identified and 4546 unique proteins were detected at $95 \%$ confidence level. Furthermore, among the unique proteins, about $47 \%$ of them had $>10 \%$ sequence coverage, and over $52 \%$ of them matched at least two peptides, allowing to quantify their abundance more precisely. Further analysis of the 4546 quantified proteins, a total of 972 proteins were identified as differentially abundant proteins (DAPs) with significant changes ( $p$-value $<0.05$, cut-off point fixed at $>1.2$ or $<0.83$ ), including 661 proteins with increased abundance and 311 proteins with reduced abundance (Figure 2A, Tables S1 and S2). Additionally, 'volcano plot' showed the distribution of DAPs mainly located between 1.2 -fold to 2.0 -fold change while only about $12.6 \%$ of the DAPs changed by more than 2-fold (Figure 2B). 
A

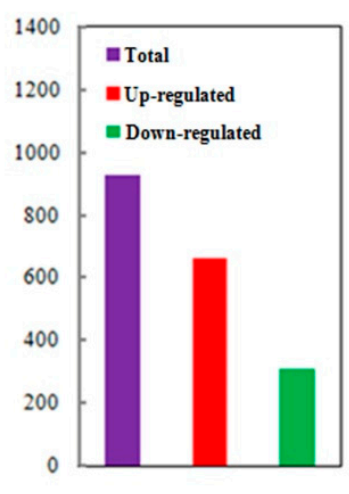

B

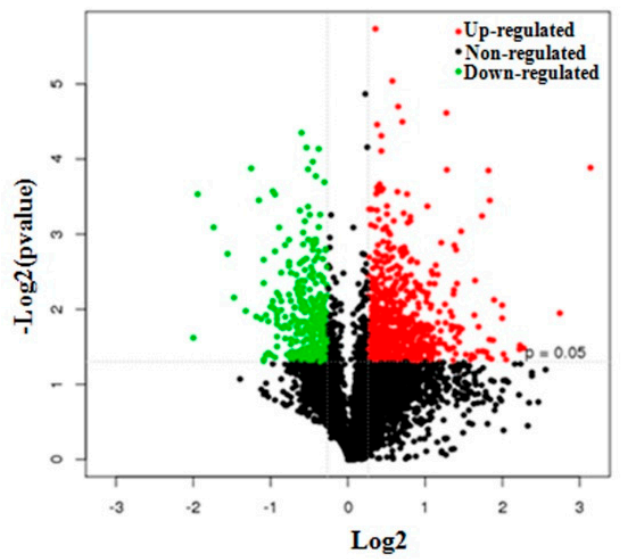

Figure 2. Summary of differentially abundant proteins (DAPs) responsive to MCMV infection. (A) The total number of DAPs containing the increased abundance and reduced abundance. The numbers above the bars are the exact numbers of DAPs. (B) Volcano plot showing distribution of the total identified protein. The $x$-axis shows various fold change groups and the $y$-axis shows the $p$ value.

\subsection{Impacts of MCMV Infection on the Maize Global Proteome}

The functions of all the identified proteins and the DAPs after MCMV infection were classified using the KOG database annotation. The results illustrated in Figure 3A revealed that 1300 identified proteins and 276 DAPs were involved in 'cellular process and signaling', and 1132 identified proteins and 233 DAPs were involved in 'metabolism'. Additionally, the category of 'information storage and processing' included 807 identified proteins and 167 DAPs, respectively.

$\mathbf{A}$

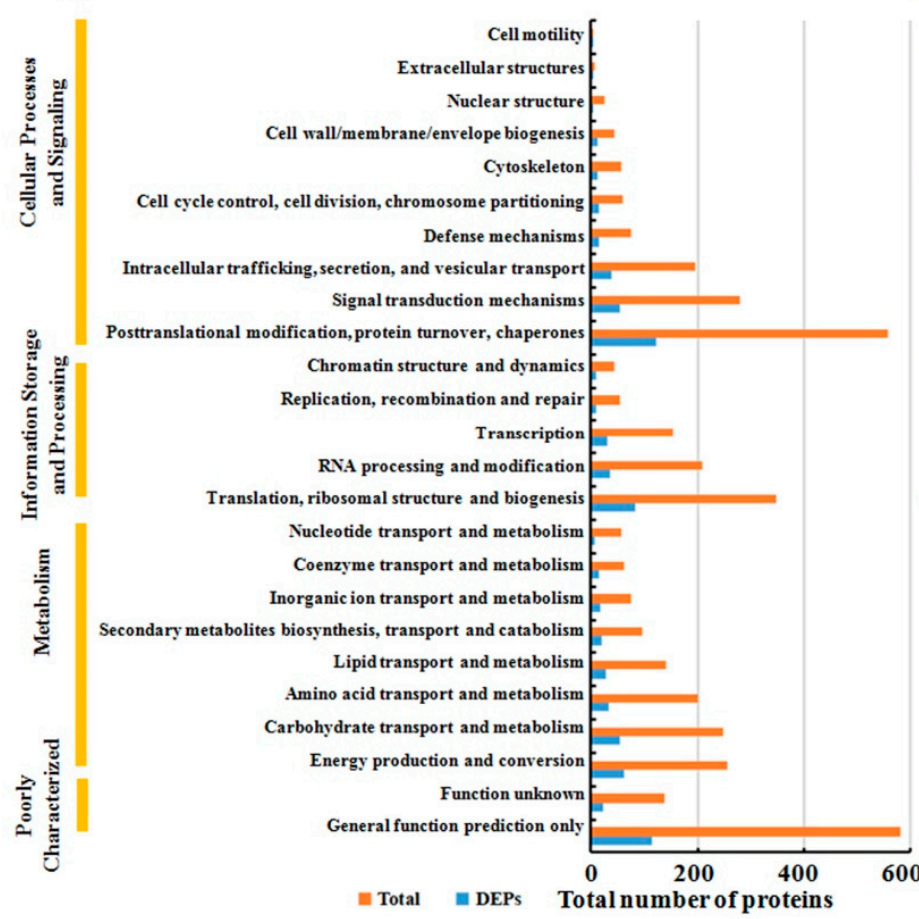

\section{B}

E chloroplast

eytosol

nuclear

mitochondria

plasma membrance

- extracellular

vacuolar

endoplasmic reticulum

endoplasmic

cytosol,nuclear

golgi apparatus

chloroplast, mitochond

nuclear,plasma membr:

cytosol,plasma membrance

endoplasmic reticulum,plasma membrance

C
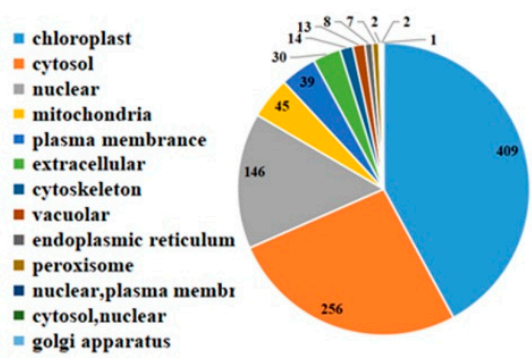

Figure 3. Classification of all identified proteins and DAPs. (A) all identified protein (orange) and DAPs (blue) are divided into different terms based on KOG analysis. Subcellular location of all identified proteins $(\mathbf{B})$ and DAPs $(\mathbf{C})$. 
All identified proteins and DAPs were further assorted according to their subcellular locations (Figure 3B). For identified proteins, 16 different subcellular components were found, including 1943 chloroplast-localized proteins, 1044 cytosol-localized proteins, 838 nuclear-localized proteins and 236 mitochondria-localized proteins. For DAPs, only 13 different subcellular components were found, including 409 chloroplast-localized proteins, 256 cytosol-localized proteins, 146 nuclear-localized proteins, and 45 mitochondria-localized proteins.

\subsection{GO and KEGG Analysis of DAPs under MCMV Infection}

Gene Ontology (GO) annotation showed that all DAPs were grouped into three different GO categories, containing 16 terms in the cellular component category, 11 terms in the molecular function category, and 21 terms in the biological process category (Figure 4). Among these terms, cellular process (447 DAPs), metabolic process (437 DAPs), response to stimulus (140 DAPs), biological regulation (99 DAPs), cellular component organization or biogenesis (89 DAPs), regulation of biological process (87 DAPs), and localization (83 DAPs) were the top five terms in the biological process category. Cell (529 DAPs), cell part (521 DAPs), and organelle (385 DAPs) terms in the cellular component category; and catalytic activity (476 DAPs) and binding activity (416 DAPs) terms in the molecular function category were enriched with DAPs.

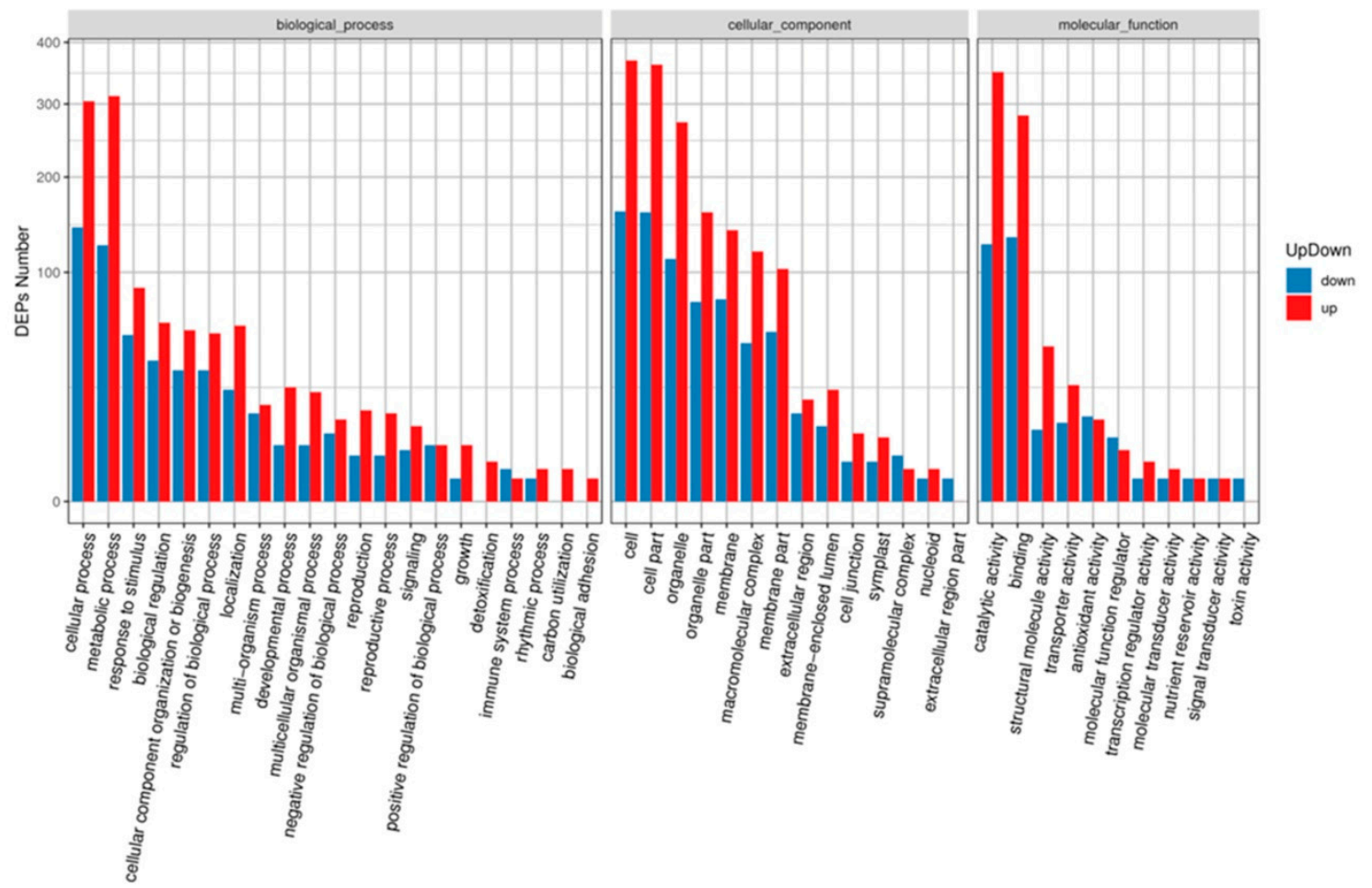

Figure 4. GO terms analysis of the DAPs identified during MCMV infection. The $x$-axis indicate the grouped GO terms containing cellular component, molecular function, and biological process. The $y$-axis shows cluster frequencies of the GO terms.

DAPs were further classified using Kyoto Encyclopedia of Genes and Genomes (KEGG) pathway annotation and enrichment analysis. The results revealed that those DAPs under MCMV infection could be divided into 115 different pathways. Among these pathways, six pathways were significantly enriched with DAPs, including ribosome, photosynthesis, protein export, fatty acid degradation, linoleic acid metabolism, and isoflavonoid biogenesis related terms (Figure 5). 


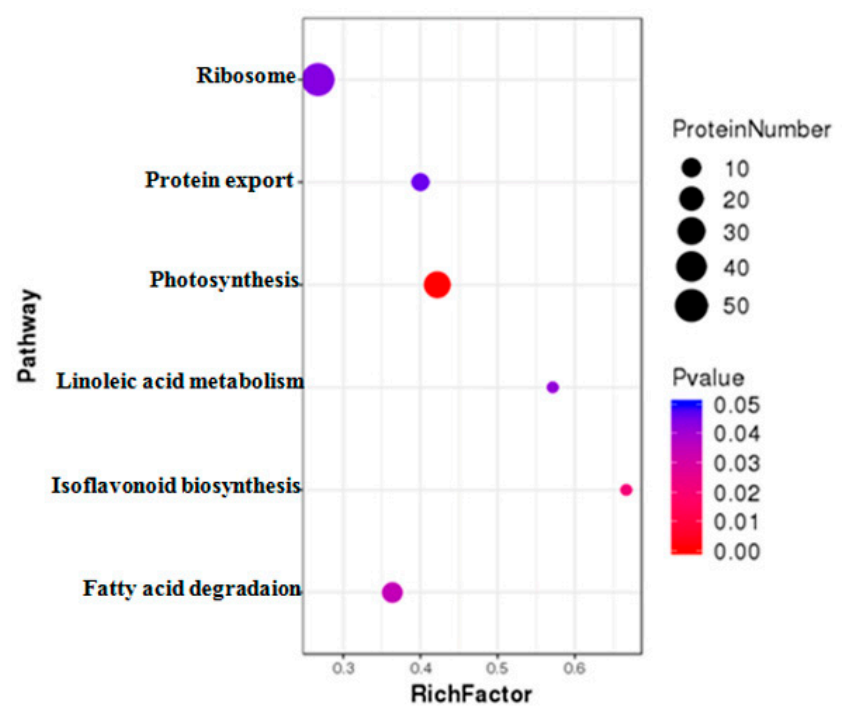

Figure 5. KEGG enrichment analysis of the DAPs identified during MCMV infection. The $y$-axis indicate the significantly enriched KEGG terms. The $x$-axis shows cluster rich factor of the KEGG terms.

\subsection{Photosynthetic Activity Decreased during MCMV Infection}

Viral infection usually triggers dramatic changes in the expression of photosynthesis-related proteins, which are important in plant-virus interactions [28]. Decreased photosynthesis, mostly at the proteome level, is usually associated with viral symptoms. Additionally, some photosynthesis-related proteins have been reported to participate in plant defense against viruses [28]. PSI and PSII core subunits and the oxygen evolving proteins are common targets for virus-induced changes [28,29]. Consistent with previous studies, our iTRAQ data and KEGG pathway annotation identified that 14 DAPs associated with photosynthesis were reduced abundance and 13 DAPs related to photosynthesis were increased abundance responsive to MCMV infection. Among these DAPs, eight PSII-associated proteins were identified as significantly modulated proteins while two oxygen-envolving enhancer proteins constituted by PsbP (GRMZM2G047954_P01, photosystem II oxygen-evolving enhancer protein 2) and PsbQ (GRMZM5G804323_P01, photosystem II oxygen-evolving enhancer protein 3) were found to downregulate 1.41-fold and 1.89-fold, respectively. The decrease in abundance of PetE (GRMZM2G071450_P01, plastocyanin) and PetF (GRMZM2G043162_P01, ferredoxin) that involve in photosynthetic electron transport was 2.1- and 1.37-fold compared to the controlled maize plants.

To further reveal the decreased abundance in these photosynthesis-related proteins interference in plant photosynthesis, the chlorophyll fluorescence parameters were measured in MCMV-infecting or controlled maize leaves. As shown in Figure 6A-E, the maximum photochemical efficiency of PSII (Fv/Fm), the actual photochemical efficiency of PSII (Y(II)), and the electron transfer rate (ETR) exhibited marked decreases after MCMV infection.

\subsection{Alteration of Ribosomal Protein Abundance during MCMV Infection}

Ribosomes are the cellular machinery needed for protein synthesis, which comprise a large (60S or 50S) subunit, a small (40S or 30S) subunit, rRNAs and other proteins. In eukaryotic cells, ribosomes are found in the cytoplasm, mitochondria, and in plant chloroplasts [30,31]. In the present study, the abundance of ribosomal proteins was altered significantly in MCMV-infected samples compared to the mock-inoculated control, as revealed by KEGG annotation and enrichment analysis. A total of 50 DAPs were annotated as ribosome-related pathways, and 40 out of them were significantly upregulated, suggesting a remarkable increase abundance in ribosomal protein levels (Table S3). Among these modulated proteins, 19 DAPs were annotated as 60S ribosomal proteins, 13 DAPs were discovered to be associated with 40 S ribosomal proteins and 10 DAPs were related to mitochondrial/chloroplast ribosomal proteins. The top hit of these DAPs in reduced abundance was 
GRMZM5G851698_P02 (annotated as 40S ribosomal protein S6) that was downregulated by 3.85-fold while the top hit of these increased abundant DAPs was GRMZM2G152573_P04 (annotated as 60s ribosomal protein L34) and GRMZM2G044800_P02 (annotated as 40S ribosomal protein S11) that were upregulated by 2.53 -fold.

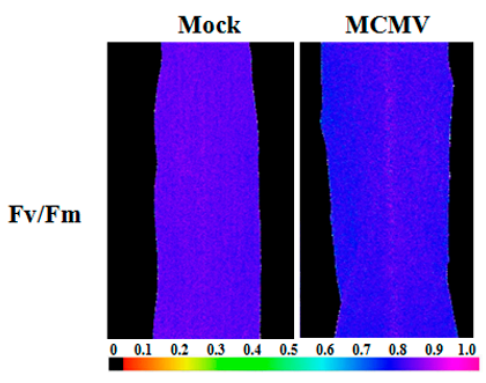

C

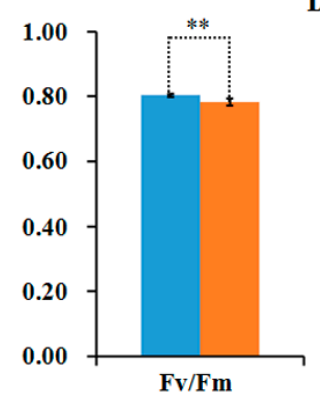

D

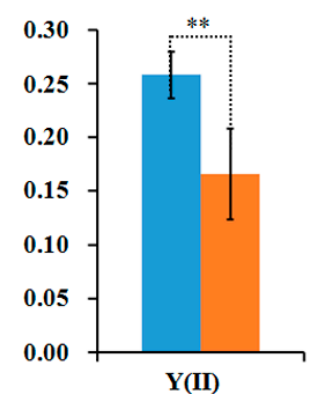

B

Y(II)

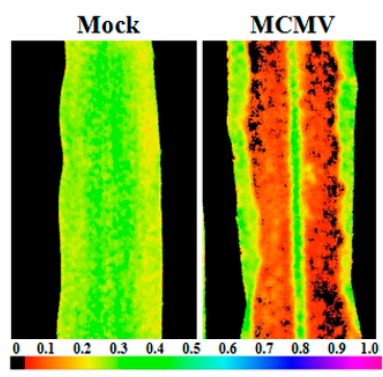

$\mathbf{E}$

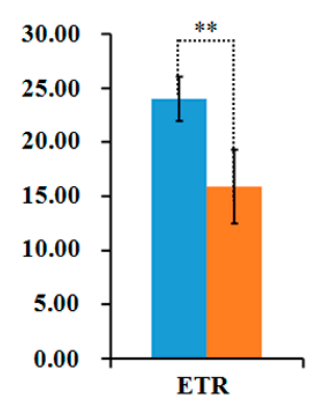

Figure 6. Detection of photosynthetic activity after MCMV infection. (A,B) Images showing the maximum photochemical efficiency $(\mathrm{Fv} / \mathrm{Fm})$ and the actual photochemical efficiency (Y(II)) of PSII of whole leaves. The color code depicted at the bottom of the image ranges from 0 (black) to 1.0 (purple). (C) Average Fv/Fm values; (D) average Y(II) values; and (E) average ETR values of whole leaves are shown. The blue denote mock-inoculated plants and the orange denote MCMV-infected plants. The bars represent the mean values, with standard errors of the mean, for one representative experiment $(n=10) .{ }^{*}$, statistically different at $p<0.05$ level.

\subsection{Enrichment of Stress Response-Related Proteins during MCMV Infection}

Plants have evolved many defense strategies to survive under abiotic and biotic stress conditions. We found that a total of 30 DAPs were annotated to be involved in defense response and response to biotic stimulus in our GO annotation result, including 17 proteins with increased abundance and 13 proteins with reduced abundance (Table S4). Among these DAPS, heat shock protein 70 (GRMZM2G428391_P01) and WD repeat-containing protein domain phosphoinositide-interacting protein 3 (GRMZM2G122607_P01) were remarkably accumulated, while ribosome-inactivating protein 2 (GRMZM2G119705_P01) and calcium-dependent protein kinases (GRMZM2G112057_P01) were markedly downregulated in response to MCMV infection. On the other hand, it was notable that the GRMZM2G156861_P01 (annotated as lipoxygenase, LOX) was upregulated by 1.28-fold while the level of GRMZM2G040095_P02 (annotated as lipoxygenase 6, LOX6) was downregulated by 1.25-fold in MCMV-infected plants compared with mock-inoculated plants, suggesting that functional segregation among different LOXs upon MCMV infection.

\subsection{Differential Regulation of Redox Homeostasis Related Proteins}

Plants defense abiotic and biotic stresses through regulating the production of reactive oxygen species (ROS) and the antioxidant machinery [32]. Interestingly, we found that the levels of several oxidation-reduction process-related proteins were significantly altered in MCMV-infected plants 
compared to the control plants (Table S5), indicating the crucial functions of antioxidation during MCMV infection. For example, the levels of 2-oxoglutarate dehydrogenase E1 (GRMZM2G151041_P01), known to recruit its E2 and E3 components to generate ROS, was increased in abundance with more than 2-fold after MCMV infection, while the level of monooxygenase (GRMZM2G089121_P02) was upregulated by 1.91 -fold. Isocitrate dehydrogenase is revealed to be an important enzyme catalyzing the reduction of $\mathrm{H}_{2} \mathrm{O}_{2}$, and in our results, isocitrate dehydrogenase 1 (GRMZM2G432128_P01) was increased in abundance with 1.88-fold. Meanwhile, a total of 20 DAPs related to cell redox homeostasis were identified through GO annotation (Table S6). Among these DAPs, protein disulfide isomerase 1 (ZmPDIL-1, GRMZM2G091481_P01) were remarkably accumulated with 1.55-fold increased abundance while peroxiredoxin-5 (ZmPrx5, GRMZM2G036921_P01) was downregulated by 1.24-fold, indicating these proteins might be important host factors involving in regulating plant resistance or tolerance to virus infection stress.

\subsection{Transcriptional Level Analysis for Selected DAPs}

To verify the changes in protein levels determined using iTRAQ analysis, 18 DAPs were selected and analyzed using qRT-PCR. Among 11 upregulated proteins identified from the iTRAQ comparative analysis, the mRNA expression levels of 10 DAPs were upregulated after MCMV infection according to qRT-PCR analysis (Figure 7A). Among seven downregulated proteins identified from the iTRAQ analysis, six were significantly downregulated at the transcriptional level after MCMV infection (Figure 7A). As shown in Fig 7B, the trend of the changes in the levels of these DAPs determined by qRT-PCR and iTRAQ analyses matched, although the value of the changes identified by the two methods did not match exactly. In addition, several proteins, such as GRMZM2G005984_P01 and GRMZM2G104384_P01 showed inconsistent results between the iTRAQ and qRT-PCR analyses. There is a large amount of evidence that transcript and protein levels do not match and our result is yet another example of this. Post-transcriptional regulation or post-translational modifications might be responsible for these differences.

$\mathbf{A}$

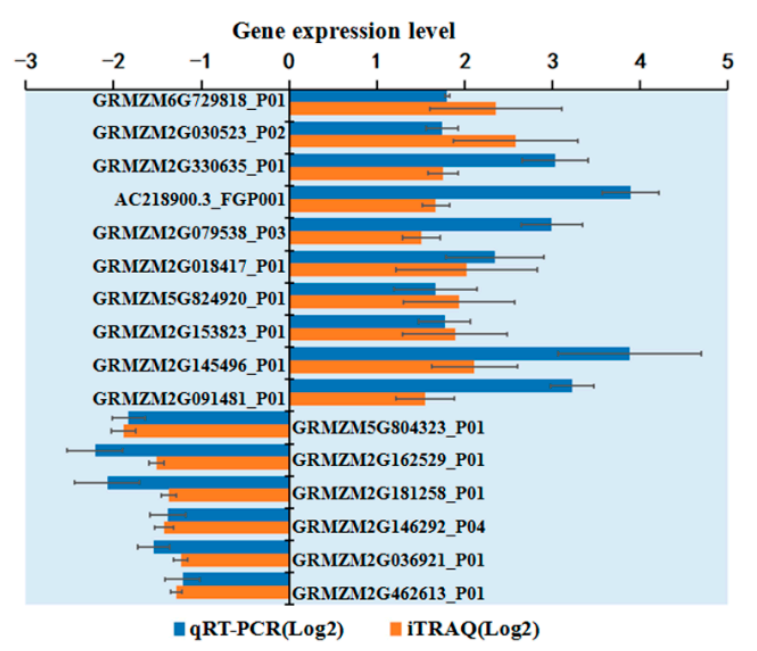

B

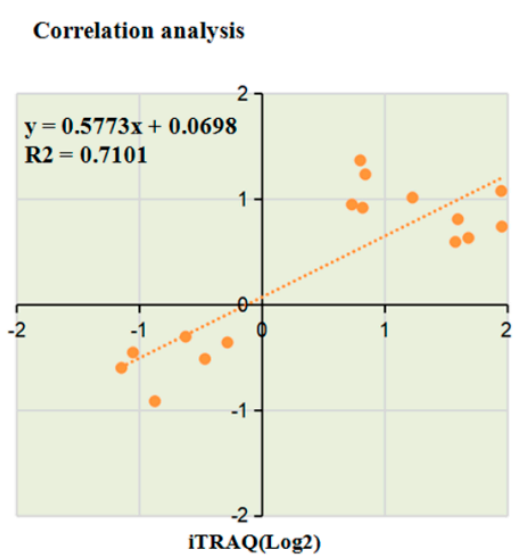

Figure 7. Transcriptional analyses of selected DAPs. (A) Transcriptional analyses of selected DAPs. The $y$-axis shows the 16 selected DAPs for the analyses. The $x$-axis indicates the relative expression levels. The bars represent the mean values, with standard errors of the mean, for one representative experiment $(n=6)$. (B) Correlation analysis of selected DAPs btween iTRAQ data and qRT-PCR analysis. The $x$-axis and $y$-axis are shown in the Log2 scale. 


\subsection{Functional Analyses of Two Selected DAPs through Virus-Induced Gene Silencing}

Compared to the mock-inoculated plants, the abundance of ZmPDIL-1 was significantly upregulated while the abundant of ZmPrx 5 was remarkably downregulated in MCMV infected maize plants. However, the differential abundance of proteins, whether up- or downregulated, does not absolutely indicate antiviral activity. Hence, we investigated the potential function(s) of the regulated proteins during MCMV infection by silencing candidate ZmPDIL-1 and ZmPrx5 in maize using a CMV-based VIGS system for genetic validation. The silencing efficiency of the target genes ZmPDIL-1 and $\mathrm{ZmPrx} 5$ was detected in young systemic leaves that did not cause obvious phenotypic changes at 15 dpi (Figures $8 \mathrm{~A}$ and $9 \mathrm{~A}$ ), based on qRT-PCR analyses. The results revealed that the ZmPDIL-1 relative transcript level in the CMV-ZmPDIL-1-inoculated plants was reduced to approximately $54 \%$, the relative transcript level of ZmPrx5 in the CMV-ZmPrx5-inoculated plants was reduced to about $45 \%$ of the value obtained from the controlled plants (Figures $8 \mathrm{~B}$ and $9 \mathrm{~B}$ ). Then, the leaves of ZmPDIL-1 and ZmPrx5-silenced B73 plants were challenged with MCMV. ELISA and qRT-PCR were used separately to analyze the accumulation of gRNA and the virus titer of MCMV in these inoculated plants. The qRT-PCR results showed that MCMV gRNA levels in the ZmPDIL-1-silenced and ZmPrx5-silenced plants were decreased to approximately $62 \%$ and $67 \%$ compared with those in the non-silenced at $11 \mathrm{dpi}$ (Figure $8 \mathrm{C}$ ). The MCMV titer in the ZmPDIL-1-silenced plants were decreased to approximately $62 \%$ and $60 \%$, respectively, compared with those in the control plants (Figures $8 \mathrm{D}$ and 9D). Consistent with the reduced MCMV accumulation in the ZmPDIL-1 and ZmPrx5-silenced plants, disease symptoms in these plants were also alleviated (Figures $8 \mathrm{E}$ and $9 \mathrm{E}$ ). All these results indicated that the abundances of ZmPDIL-1 and ZmPrx5 might play crucial roles in maize defense again MCMV infection.

A
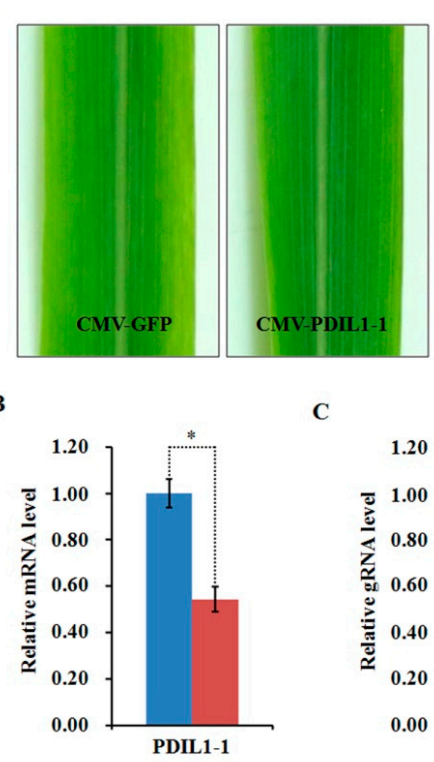

C
$\mathbf{E}$
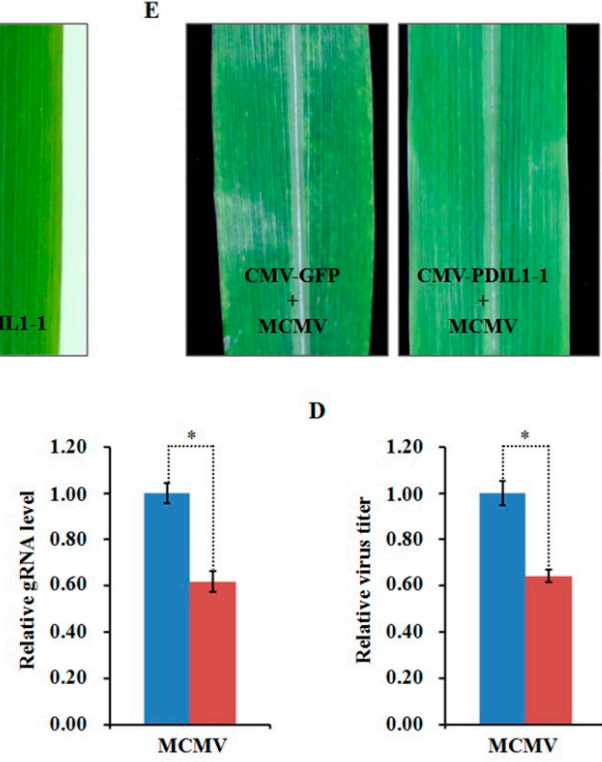

D

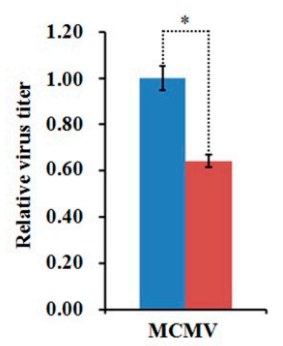

CMV-GFP

CMV-PDIL1-1

Figure 8. Effects of silencing ZmPDIL-1 expression through CMV-based VIGS on MCMV infection in maize. (A) Typical symptoms in the ZmPDIL-1-silenced B73 leaves were similar to that in the non-silenced control leaves. (B) qRT-PCR analysis of ZmPDIL-1 expression in ZmPDIL-1-silenced and control B73 plants agroinoculated with either TRV:ZmPDIL-1 or TRV:GFP. The error bars showed standard deviations. (C,D) Silencing of ZmPDIL-1 suppressed MCMV accumulation in systemic infected leaves. The gene silencing efficiency and viral gRNA accumulations were detected by qRT-PCR (C) and viral titer was determined by ELISA (D). Bars indicated the means \pm standard deviations (SD) from three independent experiments; ${ }^{*}$, statistically different at $p<0.05$ level; the results were determined by the Student's $t$-test. (E) Typical symptoms in the ZmPDIL-1-silenced or non-silenced B73 leaves inoculated with MCMV at $11 \mathrm{dpi}$. 
A

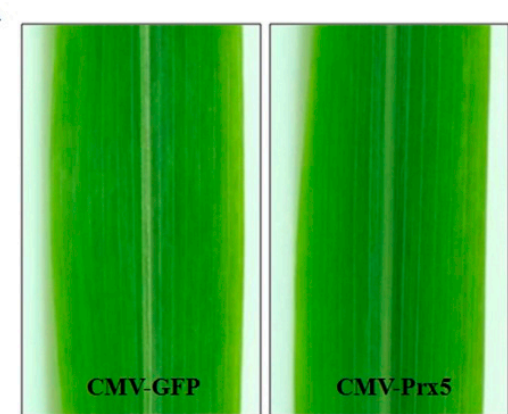

$\mathbf{E}$

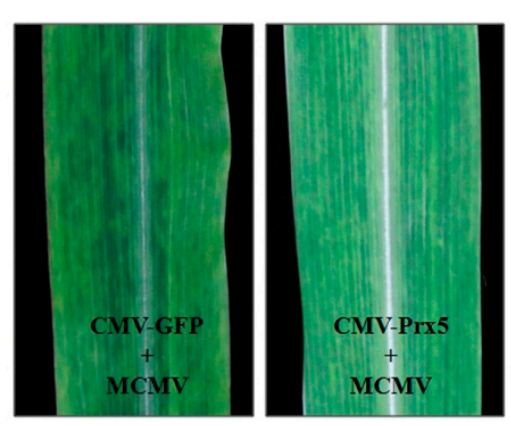

D

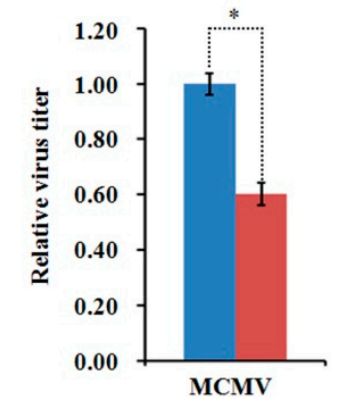

D

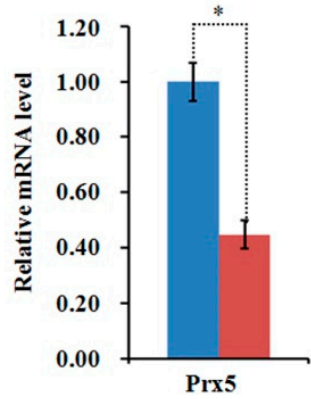

C

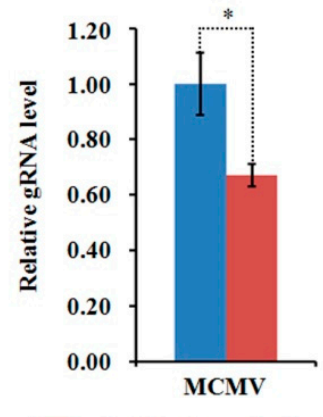

Figure 9. Effects of silencing ZmPrx5 expression through CMV-based VIGS on MCMV infection in maize. (A) Typical symptoms in the ZmPrx5-silenced B73 leaves and the non-silenced control leaves. (B) qRT-PCR analysis of ZmPrx5 expression in ZmPrx5-silenced and control B73 plants agroinoculated with either TRV:ZmPrx5 or TRV:GFP. The error bars showed standard deviations; (C,D) Silencing ZmPrx5 expression impaired MCMV accumulation in systemic infected leaves. The viral gRNA accumulations were detected by qRT-PCR (C) and viral titers was determined by ELISA (D). Bars indicated the means \pm standard deviations (SD) from three independent experiments; *, statistically different at $p<0.05$ level; the results were determined by the Student's $t$-test. (E) Typical symptoms in the ZmPrx5-silenced or non-silenced B73 leaves inoculated with MCMV at $11 \mathrm{dpi}$.

\section{Discussion}

MCMV infection has resulted in destructive losses in maize production and has rapidly spread into many regions worldwide [33]. At all growth stages, most current commercial maize cultivars are susceptible to MCMV and no extremely resistant maize cultivars have been identified [34]. Thus, there is an urgent need to determine the molecular mechanisms about how MCMV establish an infection and how the plant reacts to viral infection. Herein, an iTRAQ-based comparative proteomic approach was performed in the present study to provide the whole-proteome information during MCMV infection of maize.

\subsection{Photosynthesis Decreased during MCMV Infection}

The most common viral symptom of plant virus infection is caused by chlorosis and the subsequent loss of chlorophyll, which usually imply the occurrence of chloroplast-virus interactions. In plants, the chloroplast is not only a common target of plant virus but also the organelle that conducts photosynthesis [28]. Previous researches have indicated that decreased photosynthesis, mostly at the proteome level, is a common phenomenon in plants infected by numerous viruses including tobacco mosaic virus, cucumber mosaic virus, plum pox virus and peanut stunt virus [35-38]. A research showed seven photosynthesis-related proteins were significantly downregulated and the photosynthetic activity was strongly suppressed in the systemic leaves during SCMV infection [26]. Consistent with these previous findings, our iTRAQ-based proteomic analysis and measurement of photosynthetic 
rates both indicated maize photosynthesis was severely impaired during MCMV infection. A variety of reports suggested photosynthesis-related proteins could play active roles in plant defense viruses. Kong and associates confirmed that silencing of host Psbp, an oxygen-involving enhancer protein of PSII located in chloroplast, in both rice and Nicotiana. benthamiana enhanced host susceptibility to rice stripe virus (RSV) [29]. Moreover, overexpression of Psbp in N. benthamiana revealed that PsbP was involved in host defense response to geminivirus [39]. Similarly, Rodriguez-Herva and associates confirmed that silencing of PsbQ in tobacco compromised plant immune responses induced by Pseudomonas syringae pv tomato DC3000 [40]. In our research, PsbP and PsbQ were identified to be remarkably downregulated in response to MCMV, indicating that the virus may modulate the abundance of defense-related proteins from the chloroplast and benefit its infection.

\subsection{Ribosomal Proteins Commonly Affected by MCMV Infection}

Viruses depend on their host ribosomal machinery to synthesize viral proteins. Our comparative proteomic analysis revealed that most of the ribosome-related proteins were upregulated in response to MCMV infection. Thus, we speculated that the increase in the abundance of ribosomal proteins during MVMV infection might help host plants to survive viral infection. Further studies will be required to understand the mechanism of ribosomal proteins involved in viral translation and replication. Recently, Li and associates reported that knockdown of ribosomal proteins L18 (rpL18) reduced RSV accumulation in small brown planthopper through suppression of the interaction between rpL18 and RSV nucleocapsid protein [41]. Previous evidence also indicated that tobacco etch virus (TEV) P1 protein could specifically bind with host's 60S ribosomal subunits and stimulate protein translation in vitro translation assays [42]. Conversely, it is worth noting that a plant NSP-interacting kinase mediates nuclear trafficking of ribosomal protein L10A (rpL10A), which enhances plant resistance to geminivirus infection [43]. Furthermore, ribosomal proteins rpL12 and rpL19 were also confirmed to be important factors in non-host disease resistance in N. benthamiana and Arabidopsis against bacterial pathogens [44]. Obviously, the programming of ribosome-related proteins might maintain a balance between plant immune response to virus and viral infection.

\subsection{Stress Response-Related Proteins Regulated by MCMV Infection}

Our comparative proteomic analysis found that defense- and stimulus-related DAPs were significantly modulated in abundance after MCMV infection. Several LOXs upon MCMV infection were showed to be differently regulated, suggesting a subtle response of LOXs after MCMV infection. Previous evidences had showed that the activities of LOX-derived oxylipins were induced during defense response against diverse pathogens [45]. As known, the monocot-specific 9-LOX was required to initiate an effective jasmonate-mediated defense response against Fusarium verticillioides in diverse maize tissues [46]. Also, the abundance of endogenous 9-LOX was highly induced after agro-infiltration with TMV-based construct in N. benthamiana [45]. Not only the expression change of diverse LOXs, in our study, the abundance of ribosome-inactivating protein 2 and HSP70 were also altered in response to MCMV infection. Homologous proteins of ribosome-inactivating protein from the genus Phytolacca were reported to mediate a broad-spectrum antipathogenic activities [47]. In addition, heat shock protein were revealed to act as one of the major chaperones and involved in plant immunity and stress responses [48]. For example, maize HSP70 is reported to involve ABA-induced tolerance to drought and heat stress combination [49].

\subsection{Redox Regulation in Maize after MCMV Infection}

The rapid ROS production, known as the oxidative burst, is the earliest defense response employed by plants [50]. ROS are the primary signals during plant defense response and interact with plant hormones, nitric oxide, mitogen-activated protein kinases (MAPKs), and many other signal compounds [51-53]. However, in host cells, highly reactive ROS can cause oxidative damage. Considering their toxicity and important role in signaling, the ROS level in cells must be tightly 
regulated. Thus, plants have evolved an enzymatic ROS scavenging system including different enzymes such as catalases (CAT), peroxidases (POD), and superoxide dismutases (SOD) to maintain a balance of endogenous ROS [50]. Previous studies on maize pathogens indicated that CAT activity was significantly increased in maize lines resistant to Aspergillus flavus infection and SOD activity was remarkably promoted on maize roots during F. verticillioides infection [54,55]. Huang and associates revealed that combined expression of APX and glutathione peroxidase contributed to maize defense response against Curvularia lunata by modulating the balance of ROS [56]. For viral infection, in SCMV-infected maize leaves, the proteomic level of polyamine oxidase (PAO) that catalyzes the production of $\mathrm{H}_{2} \mathrm{O}_{2}$ was upregulated, while the level of APX was strongly suppressed [26]. Consistent with these previous reports, in the present study we also found that 2-oxoglutarate dehydrogenase E1, a component that plays vital role in the generation of ROS, was increased in abundance while two scavenging enzymes, monooxygenase and isocitrate dehydrogenase, showed decreased abundance in MCMV-infected leaves. Obviously, our iTRAQ data suggested that maintaining redox dynamic balance in maize is required during MCMV infection.

\subsection{ZmPDIL-1 Facilitates MCMV Infection}

The family of protein disulfide isomerases (PDIs), which is highly conserved across eukaryotic species, is composed of several well-characterized proteins containing catalytic sites similar to those of thioredoxin [57]. PDIs have been shown to be involved not only in the folding of nascent polypeptides, but also in the formation of disulfide bonds in the endoplasmic reticulum [58]. Previous reports identified that PDIs inhibitor significantly reduced the replication of multiple human and animal viruses such as dengue virus, influenza $A$, and influenza B viruses $[59,60]$. In plants, the ER-resident PDIs are also known to have chaperone activities [61], and required for $N$-mediated resistance to TMV through accelerate the accumulation of induced receptor-like kinase during plant innate immunity [62]. In addition, a PDI-like protein HvPDIL5-1 derived from barley was confirmed to function as a susceptibility factor to bymoviruses infection [63]. Similarly, the iTRAQ analyses revealed that maize PDIL expression is upregulated in leaf tissues after SCMV infection, and knockdown of PDIL through brome mosaic virus-based VIGS can impair SCMV replication [26]. In the present study, we determined that ZmPDIL-1 was upregulated at both the protein and transcription levels after MCMV infection. Furthermore, the accumulation of MCMV in ZmPDIL-1-silenced maize plants was significantly decreased, suggesting that maize ZmPDIL-1 might be a common susceptibility factor to virus infection. However, it remains to be determined whether ZmPDIL-1 functions as a molecular chaperone for assisting correct folding of viral protein(s) or activating the host protein(s) involved in regulating virus infection.

\subsection{ZmPrx5 Is a Positive Regulator of MCMV Infection}

Peroxiredoxin protein (Prx) participates in the active oxygen scavenging through the oxidation of the conserved cysteine residue and reduction the ROS [64]. Several reports suggested that Prx contributed to propagation of human and animal viruses. Watanabe and associates found that knockdown of Peroxiredoxin 1 (Prx 1) by RNA interfering resulted in a significant reduction of measles Virus (MeV) replication [65]. Further study showed that Prx1 might serve as a host factor binding to MeV-NTAIL (the C-terminal region of the nucleoprotein) and positively regulated the transcription and replication of MeV [65]. Also, Deng and associates revealed that Prx1 could interacts with exosome component 5 and negatively regulate hepatitis B virus infection through RNA decay [66]. In plants, PRX genes have been characterized and mainly classified into four family members as 1-Cys Prx, 2-Cys Prx, Prx II, and Prx Q [67,68]. Kim and associates identified that overexpression of Arabidopsis 2-Cys Prx in transgenic tall fescue enhanced tolerance against methyl viologen and heat stresses [69]. Additionally, overexpression of a Prx Q homolog of Gentiana triflora in tobacco improved tolerance against fungi and enhanced anti-oxidation ability [70]. In the present study, our results indicated that silencing of ZmPrx5 through VIGS reduced the accumulation of MCMV in maize, indicating intracellular peroxiredoxin 
homeostasis may play a positive role in MCMV infection. However, the mechanisms whereby ZmPrx5 regulating MCMV propagation are still unknown. Our efforts are underway to identify viral protein(s) that might interaction with ZmPrx5.

\section{Materials and Methods}

\subsection{Plant Growth and Virus Inoculation}

The lowest two leaves on each 4-leaf stage maize cv. B73 plant were mechanically inoculated with crude extracts from MCMV-infected maize leaf tissues. The inoculated plants were grown in growth chambers with a 16:10 h (light: dark photoperiod) and $28: 25^{\circ} \mathrm{C}$ (day: night temperature cycle).

\subsection{Sample Preparation}

Leaves were collected at 11 days post inoculation (dpi) and stored at $-80{ }^{\circ} \mathrm{C}$ until further use. For each treatment, two biological replicates with five individual plants each were used for the iTRAQ-based assay. The urea extraction method described by Sheoran et al. was used to extract total proteins from individual samples [71]. The concentrations of protein samples were measured using a Pierce $^{\mathrm{TM}}$ Coomassie Plus (Bradford) Assay Kit (Thermo Fisher Scientific, Wilmington, NC, USA) and protein samples were kept at $-80^{\circ} \mathrm{C}$ for later analysis.

\section{3. iTRAQ Labeling and Strong-Cation-Exchange (SCX) Fractionation}

Total protein $(100 \mu \mathrm{g})$ from each sample was mixed with Trypsin Gold (Promega, Madison, WI, USA) at a ratio of $30: 1(v / v)$ and incubated at $37^{\circ} \mathrm{C}$ for $16 \mathrm{~h}$. Thereafter, vacuum centrifugation was used to dry the released peptides, which then reconstituted in $0.5 \mathrm{M}$ tetraethyl-ammonium bromide (TEAB). The 8-plex iTRAQ reagent (Applied Biosystems, Foster City, CA, USA) was used to further process the samples, according to the manufacturer's protocol. One unit of iTRAQ reagent was mixed with $24 \mu \mathrm{L}$ of isopropanol. The protein samples were labeled with the iTRAQ tags to achieve sample M1-113 tag, sample M2-115 tag, sample Mock1-118 tag, and sample Mock1-121 tag. After labeling, the samples were incubated at room temperature for $2 \mathrm{~h}$, pooled, and then dried by vacuum centrifugation. Then, SCX chromatography was performed with a LC-20AB HPLC Pump system (Shimadzu, Kyoto, Japan) as described [72]. Briefly, the iTRAQ labeled peptide samples were individually mixed with $4 \mathrm{~mL}$ of buffer $\mathrm{A}\left(25 \mathrm{mM} \mathrm{NaH}_{2} \mathrm{PO}_{4}\right.$ in $25 \% \mathrm{ACN}$, pH 2.7) and loaded onto a $4.6 \times 250 \mathrm{~mm}$ Ultremex SCX column containing $5 \mu \mathrm{m}$ particles (Phenomenex, Torrance, CA, USA). The peptides were eluted at a flow rate of $1 \mathrm{~mL} / \mathrm{min}$ with a linear gradient of buffer $\mathrm{B}\left(25 \mathrm{mM} \mathrm{NaH}_{2} \mathrm{PO}_{4}, 1 \mathrm{M} \mathrm{KCl}\right.$ in $25 \% \mathrm{ACN}$, $\mathrm{pH}$ 2.7). The gradient was as followed: $5 \mathrm{~min}$ in $5 \%$ buffer B, $27 \mathrm{~min}$ in $5-60 \%$ buffer B, 2 min in 60-100\% buffer B. The system was then maintained in 100\% buffer B for $1 \mathrm{~min}$. The eluted fractions were collected at $1 \mathrm{~min}$ intervals and monitored by measuring the absorbance at $214 \mathrm{~nm}$. The fractions obtained were pooled into 20 fractions, subjected to desalting using a Strata X C18 column, and dried under a vacuum.

\subsection{Liquid Chromatography-Tandem Mass Spectrometry (LC-MS/MS)}

Peptides from each fraction was resuspended in buffer A ( $2 \% \mathrm{ACN}, 0.1 \% \mathrm{FA})$ and centrifuged at $20,000 \times g$ for $10 \mathrm{~min}$. The final concentration of peptide was about $0.5 \mu \mathrm{g} / \mu \mathrm{L}$ on average. A $10 \mu \mathrm{L}$ sample was loaded onto a LC-20AD nano-HPLC column (Shimadzu, Kyoto, Japan) using an autosampler into a $2 \mathrm{~cm} \mathrm{C18} \mathrm{trap} \mathrm{column} \mathrm{at} 8 \mu \mathrm{L} / \mathrm{min}$ flow rate. Then the peptides were eluted onto a $10 \mathrm{~cm}$ analytical $\mathrm{C} 18$ column (inner diameter $75 \mu \mathrm{m}$ ) packed in-house, at a flow rate of $1 \mathrm{~mL} / \mathrm{min}$ with a linear gradient of buffer B (95\% ACN, 0.1\% FA). The gradient was as followed: 5 min in 5\% buffer B, 35 min in 5-35\% buffer $\mathrm{B}$, followed by a 5 min linear gradient to $60 \%$ and 2 min linear gradient to $80 \%$, maintained at $80 \%$ B for $4 \mathrm{~min}$, and finally a return to $5 \%$ in $1 \mathrm{~min}$. The MS analysis was performed using a a TripleTOF 5600 System (AB SCIEX, Concord, ON). Intact peptides were detected in the Orbitrap at a resolution of 30,000 and were selected for MS/MS using high-energy collision dissociation (HCD) 
operating mode with a normalized collision energy setting of 27.0, and ion fragments were detected in the Orbitrap at a resolution of 19,000. For MS1 scans, the m/z scan range was 350 to 2000 Da. For MS2 scans, the $\mathrm{m} / \mathrm{z}$ scan range was 100 to $1,800 \mathrm{Da}$.

\subsection{Proteomics Data Analysis}

Protein identification was performed by searching the Mascot database (version 2.3.02, Matrix Science, London, UK). The peptides' charge states were set to +2 and +3 . Specifically, in Mascot, an automatic decoy database search was performed, by selecting the decoy checkbox. This generates a random sequence of the database that is tested for the raw spectra and used as the real database. To decrease the likelihood of false positive peptide identification, only those peptides with a 95\% confidence interval greater than 'identity', as set by a Mascot probability analysis, were counted as identified. Each confidently identified protein involved at least one unique peptide. To quantify the proteins, each protein was required to contain at least two unique spectra. IQuant was used for protein quantification with VSN normalization. For each protein, IQuant provided a significance evaluation that was corrected for multiple hypothesis testing by the Benjamini-Hochberg method. As described previously [73], proteins were considered as significantly differently abundant if they had $p$-values $\leq 0.05$ and mean fold change $\geq 1.2$ or $\leq 0.83$.

Proteome Discoverer 1.2 software (version PD 1.2, Thermo, SanJose, CA) was used to convert the Orbitrap-generated raw data into MGF files. The Mascot search engine was used to identify the proteins using a database containing the B73 maize genome sequences (https://www.maizegdb.org; B73 RefGen v3), the non-redundant protein database (NR; NCBI) and Maize SwissProt database. All raw MS files are publicly available for download from the proteomic data repository webserver, iProX (http://www.iprox.org/) with the project number IPX0001435000.

\subsection{Annotation of the Proteins}

The identified proteins were functionally annotated using gene ontology (GO) analysis in the Blast2GO program. To classify and group the identified proteins, the Kyoto Encyclopedia of Genes and Genomes (KEGG) (http://www.genome.jp/kegg/) and Clusters of Orthologous Groups (COG) databases (http://www.ncbi.nlm.nih.gov/COG/) were used.

\subsection{Enzyme-Linked Immunosorbent Assay (ELISA)}

ELISA assays were conducted as described previously [73]. For samples co-infected with MCMV and SCMV, two duplicated plates were used, and one was incubated with a MCMV-specific monoclonal antibody [73] and the other was incubated with a SCMV-specific monoclonal antibody [74].

\subsection{Total RNA Extraction and $q R T-P C R$ Assay}

Total RNA from individual samples was isolate using the TRIzol Reagent (Invitrogen, Carlsbad, CA, USA). A nano-drop spectrophotometer (Thermo Fisher Scientific) was used to monitor the concentration and quality of the total RNA samples, followed by agarose gel electrophoresis. For each RNA sample, the concentration was adjusted to $1 \mu \mathrm{g} / \mu \mathrm{L}$. Reverse transcription (RT) was then performed using $1 \mu \mathrm{g}$ of total RNA in each $20 \mu \mathrm{L}$ RT reaction using the ReverTra Ace qPCR RT Kit (TOYOBO, Osaka, Japan). To confirm the results from the iTRAQ-based proteomic analyses, the RNA transcript levels of 27 randomly selected differentially expressed proteins (DAPs) were determined by qPCR using the LightCycler 480@ SYBR Green I Master (Roche Applied Science, Basel, Switzerland). For each gene, three technical replicates were used during qPCR to calculate the gene's relative expression. Gene expression was normalized against the expression level of maize endogenous elongation factor- 1 A gene (EF-1A). The primers used for PCR or qRT-PCR are listed in Table S7. Cucumber mosaic virus-based virus-induced gene silencing (CMV-VIGS) plasmid construction and maize inoculation

CMV-VIGS in maize was conducted as described by Wang et al. with minor modifications [75]. Briefly, construct pCMV101, pCMV301, or the pCMV201 derivatives were transformed into the C58C1 
strain of Agrobacterium tumefaciens. Cultures of agrobacterium containing pCMV101, pCMV301, and one of the PCMV201 derivatives were co-infiltrated into Nicotiana benthamiana leaves. At 4 dpi, the infiltrated $N$. benthamiana leaves were harvested, ground in phosphate buffer $(0.1 \mathrm{M}, \mathrm{pH} 7.0)$, and subjected to centrifugation at $3000 \times \mathrm{g}$ at $4{ }^{\circ} \mathrm{C}$ for $3 \mathrm{~min}$. The vascular puncture inoculation (VPI) method was used to inoculate maize seeds with the recovered supernatants. Seeds of maize cv. B73 were soaked for $30 \mathrm{~min}$ in tap water at room temperature. Virus-containing supernatant was pipetted onto the surface of a seed alongside the embryo ( $15 \mu \mathrm{L}$ per kernel) and a vibrating engraving tool was used to inoculate the supernatant into the underlying vascular bundles. The control comprised a vector carrying a fragment $(254 \mathrm{bp})$ of the green florescent protein (GFP) gene. The inoculated seeds were incubated for 2 days in the dark at $25^{\circ} \mathrm{C}$ and then transplanted into pots containing soil. The resulting plants were cultured in a growth chamber with a 16:8 h light and dark photoperiod set at $28: 25^{\circ} \mathrm{C}$ (day:night). For each treatment, 30-40 seeds were inoculated.

\subsection{Measurements of Photosynthetic Parameters}

The effects of MCMV on maize photosynthesis were determined with Imaging PAM (IMAG-MAXI; Heinz Walz, Effeltrich, Germany) as described previously [2].

\section{Conclusions}

In the present study, we performed iTRAQ-based quantitative proteomic analysis to investigate the responses of maize to MCMV infection. In the paired comparisons of MCMV infection and mock-inoculated samples, a total of 972 proteins were identified as DAPs with significant changes. The differential abundance of the majority DAPs involved in photosynthetic metabolism and ribosome-related pathways, and those related to stress responses and redox regulation were remarkably induced during MCMV infection. Furthermore, the roles of two candidates, ZmPDIL-1 and ZmPrx5, were investigated using CMV-induced gene silencing approach. Our results indicated that combining comparative proteomic analyses and virus-induced gene silencing can assist in identifying host proteins modulating MCMV infection and might contribute to provide guidelines for designing antiviral strategies.

Supplementary Materials: Supplementary materials can be found at http://www.mdpi.com/1422-0067/21/1/35/s1. Author Contributions: Conceived and designed the experiments: J.W., X.Z., and Y.Q. Performed the experiments and analyzed the data: M.D., Q.C., and Y.H. Wrote the paper: M.D. and Y.Q. All authors have read and agreed to the published version of the manuscript.

Funding: This work was supported by the National Natural Science Foundation of China (grant no. 31671997) and the National Key Research and Development Project of China (grant no. 2017YFD0201604).

Acknowledgments: We are grateful to Tao Zhou from China Agricultural University for providing the CMV-VIGS vector.

Conflicts of Interest: The authors declare no conflict of interest.

\section{Abbreviations}

$\begin{array}{ll}\text { MCMV } & \text { chlorotic mottle virus } \\ \text { CMV } & \text { cucumber mosaic virus } \\ \text { SCMV } & \text { sugarcane mosaic virus } \\ \text { MDMV } & \text { maize dwarf mosaic virus } \\ \text { Mev } & \text { measles Virus } \\ \text { sgRNAs } & \text { subgenomic RNAs } \\ \text { LOP } & \text { lipoxygenase } \\ \text { ROS } & \text { reactive oxygen species } \\ \text { HSP } & \text { heat shock protein } \\ \text { CAT } & \text { catalases }\end{array}$


POD peroxidases

SOD superoxide dismutases

PDI protein disulfide isomerases

Prx peroxiredoxin protein

\section{References}

1. Allie, F.; Rey, M.E.C. Transcriptional alterations in model host, Nicotiana benthamiana, in response to infection by South African cassava mosaic virus. Eur. J. Plant Pathol. 2013, 137, 765-785. [CrossRef]

2. Hou, H.W.; Hu, Y.; Wang, Q.; Xu, X.B.; Qian, Y.J.; Zhou, X.P. Gene Expression Profiling Shows That NbFDN1 Is Involved in Modulating the Hypersensitive Response-Like Cell Death Induced by the Oat dwarf virus RepA Protein. Mol. Plant Microbe Interact. 2018, 31, 1006-1020. [CrossRef]

3. Khan, A.; Luqman, S.; Masood, N.; Singh, D.K.; Saeed, S.T.; Samad, A. Eclipta yellow vein virus enhances chlorophyll destruction, singlet oxygen production and alters endogenous redox status in Andrographis paniculata. Plant Physiol. Biochem. 2016, 104, 165-173. [CrossRef]

4. Li, J.J.; Henty-Ridilla, J.L.; Staiger, B.H.; Day, B.; Staiger, C.J. Capping protein integrates multiple MAMP signalling pathways to modulate actin dynamics during plant innate immunity. Nat. Commun. 2015, 6, 7206. [CrossRef]

5. Pusztahelyi, T.; Holb, I.J.; Pocsi, I. Secondary metabolites in fungus-plant interactions. Front. Plant Sci. 2015, 6, 573. [CrossRef]

6. Simon, C.; Langlois-Meurinne, M.; Bellvert, F.; Garmier, M.; Didierlaurent, L.; Massoud, K.; Chaouch, S.; Marie, A.; Bodo, B.; Kauffmann, S.; et al. The differential spatial distribution of secondary metabolites in Arabidopsis leaves reacting hypersensitively to Pseudomonas syringae pv. tomato is dependent on the oxidative burst. J. Exp. Bot. 2010, 61, 3355-3370. [CrossRef]

7. Yang, L.; Qin, L.; Liu, G.S.; Peremyslov, V.V.; Dolja, V.V.; Wei, Y.D. Myosins XI modulate host cellular responses and penetration resistance to fungal pathogens. Proc. Natl. Acad. Sci. USA 2014, 111, 13996-14001. [CrossRef]

8. Cheng, X.J.; He, B.; Chen, L.; Xiao, S.Q.; Fu, J.; Chen, Y.; Yu, T.Q.; Cheng, Z.Q.; Feng, H. Transcriptome analysis confers a complex disease resistance network in wild rice Oryza meyeriana against Xanthomonas oryzae pv. oryzae. Sci. Rep. 2016, 6, 38215. [CrossRef]

9. Su, Y.C.; Xu, L.P.; Wang, Z.Q.; Peng, Q.; Yang, Y.T.; Chen, Y.; Que, Y.X. Comparative proteomics reveals that central metabolism changes are associated with resistance against Sporisorium scitamineum in sugarcane. BMC Genom. 2016, 17, 800. [CrossRef]

10. Das, P.P.; Chua, G.M.; Lin, Q.S.; Wong, S.M. iTRAQ-based analysis of leaf proteome identifies important proteins in secondary metabolite biosynthesis and defence pathways crucial to cross-protection against TMV. J. Proteom. 2019, 196, 42-56. [CrossRef]

11. Yue, R.Q.; Lu, C.X.; Han, X.H.; Guo, S.L.; Yan, S.F.; Liu, L.; Fu, X.L.; Chen, N.N.; Guo, X.H.; Chi, H.F.; et al. Comparative proteomic analysis of maize (Zea mays L.) seedlings under rice black-streaked dwarf virus infection. BMC Plant Biol. 2018, 18, 191. [CrossRef]

12. Achon, M.A.; Subira, J.; Sin, E. Seasonal occurrence of Laodelphax striatellus in Spain: Effect on the incidence of Maize rough dwarf virus. Crop Prot. 2013, 47, 1-5. [CrossRef]

13. Wang, Q.; Zhang, C.; Wang, C.Y.; Qian, Y.J.; Li, Z.H.; Hong, J.; Zhou, X.P. Further characterization of Maize chlorotic mottle virus and its synergistic interaction with Sugarcane mosaic virus in maize. Sci. Rep. 2017, 7, 39960. [CrossRef]

14. Scheets, K. Maize chlorotic mottle machlomovirus and wheat streak mosaic rymovirus concentrations increase in the synergistic disease corn lethal necrosis. Virology 1998, 242, 28-38. [CrossRef]

15. Nutter, R.C.; Scheets, K.; Panganiban, L.C.; Lommel, S.A. The Complete Nucleotide-Sequence of the Maize Chlorotic Mottle Virus Genome. Nucleic Acids Res. 1989, 17, 3163-3177. [CrossRef]

16. Scheets, K. Analysis of gene functions in Maize chlorotic mottle virus. Virus Res. 2016, 222, 71-79. [CrossRef]

17. Scheets, K. Maize chlorotic mottle machlomovirus expresses its coat protein from a 1.47-kb subgenomic RNA and makes a 0.34-kb subgenomic RNA. Virology 2000, 267, 90-101. [CrossRef]

18. Boulila, M. Positive selection, molecular recombination structure and phylogenetic reconstruction of members of the family Tombusviridae: Implication in virus taxonomy. Genet. Mol. Biol. 2011, 34, 647-660. [CrossRef] 
19. Scheets, K.; Jordan, R.; White, K.A.; Hernandez, C. Pelarspovirus, a proposed new genus in the family Tombusviridae. Arch. Virol. 2015, 160, 2385-2393. [CrossRef]

20. Shi, F.M.; Zhang, Y.H.; Wang, K.Q.; Meng, Q.L.; Liu, X.L.; Ma, L.G.; Li, Y.C.; Liu, J.; Ma, L. Expression profile analysis of maize in response to Setosphaeria turcica. Gene 2018, 659, 100-108. [CrossRef]

21. Wang, Y.P.; Zhou, Z.J.; Gao, J.Y.; Wu, Y.B.; Xia, Z.L.; Zhang, H.Y.; Wu, J.Y. The Mechanisms of Maize Resistance to Fusarium verticillioides by Comprehensive Analysis of RNA-seq Data. Front. Plant Sci. 2016, 7, 1654. [CrossRef] [PubMed]

22. Cao, N.; Zhan, B.H.; Zhou, X.P. Nitric Oxide as a Downstream Signaling Molecule in Brassinosteroid-Mediated Virus Susceptibility to Maize Chlorotic Mottle Virus in Maize. Viruses 2019, 11, 368. [CrossRef] [PubMed]

23. Kebede, A.Z.; Johnston, A.; Schneiderman, D.; Bosnich, W.; Harris, L.J. Transcriptome profiling of two maize inbreds with distinct responses to Gibberella ear rot disease to identify candidate resistance genes. BMC Genom. 2018, 19, 131. [CrossRef] [PubMed]

24. Meyer, J.; Berger, D.K.; Christensen, S.A.; Murray, S.L. RNA-Seq analysis of resistant and susceptible sub-tropical maize lines reveals a role for kauralexins in resistance to grey leaf spot disease, caused by Cercospora zeina. BMC Plant Biol. 2017, 17, 197. [CrossRef] [PubMed]

25. Wu, L.J.; Han, Z.P.; Wang, S.X.; Wang, X.T.; Sun, A.G.; Zu, X.F.; Chen, Y.H. Comparative proteomic analysis of the plant-virus interaction in resistant and susceptible ecotypes of maize infected with sugarcane mosaic virus. J. Proteom. 2013, 89, 124-140. [CrossRef]

26. Chen, H.; Cao, Y.Y.; Li, Y.Q.; Xia, Z.H.; Xie, J.P.; Carr, J.P.; Wu, B.M.; Fan, Z.F.; Zhou, T. Identification of differentially regulated maize proteins conditioning Sugarcane mosaic virus systemic infection. New Phytol. 2017, 215, 1156-1172. [CrossRef]

27. Mostafavi, F.S.; Sabbagh, S.K.; Yamchi, A.; Nasrollanejad, S.; Panjehkeh, N. Differential molecular response of maize and Johnson grass against maize dwarf mosaic virus and bermuda grass southern mosaic virus. Acta Virol. 2019, 63, 70-79. [CrossRef]

28. Zhao, J.P.; Zhang, X.; Hong, Y.G.; Liu, Y.L. Chloroplast in Plant-Virus Interaction. Front. Microbiol. $2016,7$. [CrossRef]

29. Kong, L.F.; Wu, J.X.; Lu, L.N.; Xu, Y.; Zhou, X.P. Interaction between Rice stripe virus Disease-Specific Protein and Host PsbP Enhances Virus Symptoms. Mol. Plant 2014, 7, 691-708. [CrossRef]

30. Graf, M.; Arenz, S.; Huter, P.; Donhofer, A.; Novacek, J.; Wilson, D.N. Cryo-EM structure of the spinach chloroplast ribosome reveals the location of plastid-specific ribosomal proteins and extensions. Nucleic Acids Res. 2017, 45, 2887-2896. [CrossRef]

31. Mower, J.P.; Bonen, L. Ribosomal protein L10 is encoded in the mitochondrial genome of many land plants and green algae. BMC Evol. Biol. 2009, 9, 265. [CrossRef] [PubMed]

32. Gleason, C.; Huang, S.B.; Thatcher, L.F.; Foley, R.C.; Anderson, C.R.; Carroll, A.J.; Millar, A.H.; Singh, K.B. Mitochondrial complex II has a key role in mitochondrial-derived reactive oxygen species influence on plant stress gene regulation and defense. Proc. Natl. Acad. Sci. USA 2011, 108, 10768-10773. [CrossRef] [PubMed]

33. Braidwood, L.; Quito-Avila, D.F.; Cabanas, D.; Bressan, A.; Wangai, A.; Baulcombe, D.C. Maize chlorotic mottle virus exhibits low divergence between differentiated regional sub-populations. Sci. Rep. 2018, 8, 1173. [CrossRef] [PubMed]

34. Jones, M.W.; Penning, B.W.; Jamann, T.M.; Glaubitz, J.C.; Romay, C.; Buckler, E.S.; Redinbaugh, M.G. Diverse Chromosomal Locations of Quantitative Trait Loci for Tolerance to Maize chlorotic mottle virus in Five Maize Populations. Phytopathology 2018, 108, 748-758. [CrossRef]

35. Das, P.P.; Lin, Q.S.; Wong, S.M. Comparative proteomics of Tobacco mosaic virus-infected Nicotiana tabacum plants identified major host proteins involved in photosystems and plant defence. J. Proteom. 2019, 194, 191-199. [CrossRef]

36. Novakova, S.; Danchenko, M.; Skultety, L.; Fialova, I.; Leskova, A.; Beke, G.; Flores-Ramirez, G.; Glasa, M. Photosynthetic and Stress Responsive Proteins Are Altered More Effectively in Nicotiana benthamiana Infected with Plum pox virus Aggressive PPV-CR versus Mild PPV-C Cherry-Adapted Isolates. J. Proteome Res. 2018, 17, 3114-3127. [CrossRef]

37. Wrzesinska, B.; Vu, L.D.; Gevaert, K.; De Smet, I.; Obrepalska-Steplowska, A. Peanut Stunt Virus and Its Satellite RNA Trigger Changes in Phosphorylation in N-benthamiana Infected Plants at the Early Stage of the Infection. Int. J. Mol. Sci. 2018, 19, 3223. [CrossRef] 
38. Di Carli, M.; Villani, M.E.; Bianco, L.; Lombardi, R.; Perrotta, G.; Benvenuto, E.; Donini, M. Proteomic Analysis of the Plant-Virus Interaction in Cucumber Mosaic Virus (CMV) Resistant Transgenic Tomato. J. Proteome Res. 2010, 9, 5684-5697. [CrossRef]

39. Gnanasekaran, P.; Ponnusamy, K.; Chakraborty, S. A geminivirus betasatellite encoded beta C1 protein interacts with PsbP and subverts PsbP-mediated antiviral defence in plants. Mol. Plant Pathol. 2019, 20, 943-960. [CrossRef]

40. Rodriguez-Herva, J.J.; Gonzalez-Melendi, P.; Cuartas-Lanza, R.; Antunez-Lamas, M.; Rio-Alvarez, I.; Li, Z.; Lopez-Torrejon, G.; Diaz, I.; del Pozo, J.C.; Chakravarthy, S.; et al. A bacterial cysteine protease effector protein interferes with photosynthesis to suppress plant innate immune responses. Cell. Microbiol. 2012, 14, 669-681. [CrossRef]

41. Li, S.; Li, X.; Zhou, Y.J. Ribosomal protein L18 is an essential factor that promote rice stripe virus accumulation in small brown planthopper. Virus Res. 2018, 247, 15-20. [CrossRef] [PubMed]

42. Martinez, F.; Daros, J.A. Tobacco Etch Virus Protein P1 Traffics to the Nucleolus and Associates with the Host 60S Ribosomal Subunits during Infection. J. Virol. 2014, 88, 10725-10737. [CrossRef] [PubMed]

43. Carvalho, C.M.; Santos, A.A.; Pires, S.R.; Rocha, C.S.; Saraiva, D.I.; Machado, J.P.B.; Mattos, E.C.; Fietto, L.G.; Fontes, E.P.B. Regulated Nuclear Trafficking of rpL10A Mediated by NIK1 Represents a Defense Strategy of Plant Cells against Virus. PLoS Pathog. 2008, 4, e1000247. [CrossRef] [PubMed]

44. Nagaraj, S.; Senthil-Kumar, M.; Ramu, V.S.; Wang, K.R.; Mysore, K.S. Plant Ribosomal Proteins, RPL12 and RPL19, Play a Role in Nonhost Disease Resistance against Bacterial Pathogens. Front. Plant Sci. 2016, 6, 1192. [CrossRef] [PubMed]

45. Huang, F.C.; Schwab, W. Cloning and characterization of a 9-lipoxygenase gene induced by pathogen attack from Nicotiana benthamiana for biotechnological application. BMC Biotechnol. 2011, 11, 30. [CrossRef]

46. Christensen, S.A.; Nemchenko, A.; Park, Y.S.; Borrego, E.; Huang, P.C.; Schmelz, E.A.; Kunze, S.; Feussner, I.; Yalpani, N.; Meeley, R.; et al. The Novel Monocot-Specific 9-Lipoxygenase ZmLOX12 Is Required to Mount an Effective Jasmonate-Mediated Defense against Fusarium verticillioides in Maize. Mol. Plant Microbe Interact. 2014, 27, 1263-1276. [CrossRef]

47. Iglesias, R.; Citores, L.; Ragucci, S.; Russo, R.; Di Maro, A.; Ferreras, J.M. Biological and antipathogenic activities of ribosome-inactivating proteins from Phytolacca dioica L. Biochim. Biophys. Acta Gen. Subj. 2016, 1860, 1256-1264. [CrossRef]

48. Park, C.J.; Seo, Y.S. Heat Shock Proteins: A Review of the Molecular Chaperones for Plant Immunity. Plant Pathol. J. 2015, 31, 323-333. [CrossRef]

49. Hu, X.L.; Liu, R.X.; Li, Y.H.; Wang, W.; Tai, F.J.; Xue, R.L.; Li, C.H. Heat shock protein 70 regulates the abscisic acid-induced antioxidant response of maize to combined drought and heat stress. Plant Growth Regul. 2010, 60, 225-235. [CrossRef]

50. Torres, M.A. ROS in biotic interactions. Physiol. Plant. 2010, 138, 414-429. [CrossRef]

51. Xu, E.J.; Brosche, M. Salicylic acid signaling inhibits apoplastic reactive oxygen species signaling. BMC Plant Biol. 2014, 14, 155. [CrossRef] [PubMed]

52. Lindermayr, C.; Durner, J. Interplay of Reactive Oxygen Species and Nitric Oxide: Nitric Oxide Coordinates Reactive Oxygen Species Homeostasis. Plant Physiol. 2015, 167, 1209-1210. [CrossRef] [PubMed]

53. Takahashi, F.; Mizoguchi, T.; Yoshida, R.; Ichimura, K.; Shinozaki, K. Calmodulin-Dependent Activation of MAP Kinase for ROS Homeostasis in Arabidopsis. Mol. Cell 2011, 41, 649-660. [CrossRef] [PubMed]

54. Magbanua, Z.V.; De Moraes, C.M.; Brooks, T.D.; Williams, W.P.; Luthe, D.S. Is catalase activity one of the factors associated with maize resistance to Aspergillus flavus? Mol. Plant Microbe Interact. 2007, 20, 697-706. [CrossRef] [PubMed]

55. Pereira, P.; Ibanez, S.G.; Agostini, E.; Etcheverry, M. Effects of maize inoculation with Fusarium verticillioides and with two bacterial biocontrol agents on seedlings growth and antioxidative enzymatic activities. Appl. Soil Ecol. 2011, 51, 52-59. [CrossRef]

56. Huang, X.L.; Liu, L.X.; Chen, J.; Zhai, Y.H. Comparative proteomic analysis of the response in resistant and susceptible maize inbred lines to infection by Curvularia lunata. Prog. Nat. Sci. Mater. Int. 2009, 19, 845-850. [CrossRef]

57. Turano, C.; Coppari, S.; Altieri, F.; Ferraro, A. Proteins of the PDI family: Unpredicted non-ER locations and functions. J. Cell. Physiol. 2002, 193, 154-163. [CrossRef] 
58. Kamauchi, S.; Wadahama, H.; Iwasaki, K.; Nakamoto, Y.; Nishizawa, K.; Ishimoto, M.; Kawada, T.; Urade, R. Molecular cloning and characterization of two soybean protein disulfide isomerases as molecular chaperones for seed storage proteins. FEBS J. 2008, 275, 2644-2658. [CrossRef]

59. Rawarak, N.; Suttitheptumrong, A.; Reamtong, O.; Boonnak, K.; Pattanakitsakul, S.N. Protein Disulfide Isomerase Inhibitor Suppresses Viral Replication and Production during Antibody-Dependent Enhancement of Dengue Virus Infection in Human Monocytic Cells. Viruses 2019, 11, 155. [CrossRef]

60. Kim, Y.; Chang, K.O. Protein disulfide isomerases as potential therapeutic targets for influenza A and B viruses. Virus Res. 2018, 247, 26-33. [CrossRef]

61. Oono, Y.; Wakasa, Y.; Hirose, S.; Yang, L.J.; Sakuta, C.; Takaiwa, F. Analysis of ER stress in developing rice endosperm accumulating beta-amyloid peptide. Plant Biotechnol. J. 2010, 8, 691-718. [CrossRef] [PubMed]

62. Caplan, J.L.; Zhu, X.H.; Mamillapalli, P.; Marathe, R.; Anandalakshmi, R.; Dinesh-Kumar, S.P. Induced ER Chaperones Regulate a Receptor-like Kinase to Mediate Antiviral Innate Immune Response, in Plants. Cell Host Microbe 2009, 6, 457-469. [CrossRef] [PubMed]

63. Yang, P.; Lupken, T.; Habekuss, A.; Hensel, G.; Steuernagel, B.; Kilian, B.; Ariyadasa, R.; Himmelbach, A.; Kumlehn, J.; Scholz, U.; et al. PROTEIN DISULFIDE ISOMERASE LIKE 5-1 is a susceptibility factor to plant viruses. Proc. Natl. Acad. Sci. USA 2014, 111, 2104-2109. [CrossRef] [PubMed]

64. Pena-Ahumada, A.; Kahmann, U.; Dietz, K.J.; Baier, M. Regulation of peroxiredoxin expression versus expression of Halliwell-Asada-Cycle enzymes during early seedling development of Arabidopsis thaliana. Photosynth. Res. 2006, 89, 99-112. [CrossRef]

65. Watanabe, A.; Yoneda, M.; Ikeda, F.; Sugai, A.; Sato, H.; Kai, C. Peroxiredoxin 1 Is Required for Efficient Transcription and Replication of Measles Virus. J. Virol. 2011, 85, 2247-2253. [CrossRef] [PubMed]

66. Deng, L.; Gan, X.; Ito, M.; Chen, M.; Aly, H.H.; Matsui, C.; Abe, T.; Watashi, K.; Wakita, T.; Suzuki, T.; et al. Peroxiredoxin 1, a Novel HBx-Interacting Protein, Interacts with Exosome Component 5 and Negatively Regulates Hepatitis B Virus (HBV) Propagation through Degradation of HBV RNA. J. Virol. 2019, 93, e02203-18. [CrossRef] [PubMed]

67. Zhang, H.H.; Xu, N.; Li, X.; Jin, W.W.; Tian, Q.; Gu, S.Y.; Sun, G.Y. Overexpression of 2-Cys Prx Increased Salt Tolerance of Photosystem. in Tobacco. Int. J. Agric. Biol. 2017, 19, 735-745. [CrossRef]

68. Bhatt, I.; Tripathi, B.N. Plant peroxiredoxins: Catalytic mechanisms, functional significance and future perspectives. Biotechnol. Adv. 2011, 29, 850-859. [CrossRef] [PubMed]

69. Kim, K.H.; Alam, I.; Lee, K.W.; Sharmin, S.A.; Kwak, S.S.; Lee, S.Y.; Lee, B.H. Enhanced tolerance of transgenic tall fescue plants overexpressing 2-Cys peroxiredoxin against methyl viologen and heat stresses. Biotechnol. Lett. 2010, 32, 571-576. [CrossRef]

70. Kiba, A.; Nishihara, M.; Tsukatani, N.; Nakatsuka, T.; Kato, Y.; Yamamura, S. A peroxiredoxin Q homolog from gentians is involved in both resistance against fungal disease and oxidative stress. Plant Cell Physiol. 2005, 46, 1007-1015. [CrossRef]

71. Sheoran, I.S.; Ross, A.R.S.; Olson, D.J.H.; Sawhney, V.K. Compatibility of plant protein extraction methods with mass spectrometry for proteome analysis. Plant Sci. 2009, 176, 99-104. [CrossRef]

72. Lau, E.; Lam, M.P.Y.; Siu, S.O.; Kong, R.P.W.; Chan, W.L.; Zhou, Z.J.; Huang, J.R.; Lo, C.; Chu, I.K. Combinatorial use of offline SCX and online RP-RP liquid chromatography for iTRAQ-based quantitative proteomics applications. Mol. Biosyst. 2011, 7, 1399-1408. [CrossRef] [PubMed]

73. Wu, J.X.; Wang, Q.; Liu, H.; Qian, Y.J.; Xie, Y.; Zhou, X.P. Monoclonal antibody-based serological methods for maize chlorotic mottle virus detection in China. J. Zhejiang Univ. Sci. B 2013, 14, 555-562. [CrossRef] [PubMed]

74. Jiang, J.X.; Chen, Z.X.; Zhou, X.P. Production of a monoclonal antibody to Sugarcane mosaic virus and its application for virus detection in China. J. Phytopathol. 2003, 151, 361-364. [CrossRef]

75. Wang, R.; Yang, X.X.; Wang, N.; Liu, X.D.; Nelson, R.S.; Li, W.M.; Fan, Z.F.; Zhou, T. An efficient virus-induced gene silencing vector for maize functional genomics research. Plant J. 2016, 86, 102-115. [CrossRef]

(C) 2019 by the authors. Licensee MDPI, Basel, Switzerland. This article is an open access article distributed under the terms and conditions of the Creative Commons Attribution (CC BY) license (http://creativecommons.org/licenses/by/4.0/). 